\title{
Los primeros dibujos y esculturas de Chillida (1948-1951)
}

\author{
Chillida's first drawings and sculptures$$
\text { (1948 - 1951) }
$$

Eduardo CHAMORRO

Universidad Complutense de Madrid

eduardochamorro@telefonica.net

\section{Resumen}

Se estudian los primeros dibujos y esculturas de Eduardo Chillida a partir de: 1) el análisis de las obras presentadas en la Exposición Retrospectiva que se hizo en el Museo Nacional Centro de Arte Reina Sofía (15 de diciembre de 1998-15 de marzo de 1999), 2) la confrontación con otras obras del mismo periodo no presentadas en la Exposición, 3) la evocación de esta etapa en la película Chillida, el arte y los sueños de 1999, 4) la entrevista de Chillida con Martín de Ugalde en 1975.

Palabras clave: Construcción, represión, desmentida

\begin{abstract}
Chillida's first drawings and sculptures are studied from: 1) the analysis of the works presented at the Retrospective Exposition "Eduardo Chillida. 19481998", Museo Nacional Centro de Arte Reina Sofía (15th of December 199815th of March 1999), 2) the comparison of other works from the same period not presented at the Exposition, 3) the evocation of this period in the film
\end{abstract}


Chillida, art and dreams from 1999, 4) the interview of Chillida with Martín de Ugalde in 1975.

Key words: Construction, Repression, Disavowal

En una línea el mundo se une, con una línea el mundo se divide.

Dibujar es hermoso y tremendo

(Eduardo Chillida)

Los artistas auténticos del presente son aquellos en cuyas obras palpita aún el estremecimiento del alba

(Theodor W. Adorno)

Antes que la morada, interroga el umbral (Edmond Jabès)

De la primera etapa de creación artística de Eduardo Chillida nos ha quedado un número significativo de dibujos y algunas esculturas en yeso y piedra. Es probable que la mayoría de los dibujos fueran realizados antes de su viaje a París. Durante su estancia en Francia (octubre de 1949 a octubre de 1951), produce varias esculturas en yeso y piedra. En las numerosas exposiciones que se han hecho a lo largo de los años la obra escultórica presentada ha sido suficientemente representativa, pero, en lo referente a los dibujos, se ha procedido a una selección que dificulta la comprensión de esta etapa y, consecuentemente, de la obra posterior del artista.

Les invito a recrear esos años. Recordemos, en primer lugar, algunos datos biográficos. En 1943 comienza Chillida en San Sebastián la preparación para los estudios de Arquitectura. Se traslada posteriormente a la Escuela de Arquitectura de la Universidad de Madrid. Abandona esos estudios y se dedica al dibujo, en la Academia de Bellas Artes de Madrid, y a la escultura, en el taller de José Martínez Repullés. En 1948 se produce la apertura de la frontera con Francia. Chillida decide acudir a la capital francesa. Estará en París dos cursos: 1949 a 1951. Retorna a San Sebastián para casarse con Pilar Belzunce el 28 de julio de 1950. Vuelve a Francia con su mujer e irá a vivir a un pequeño pueblo, Villaines-sous-Bois, al norte de París. En abril de 1951 nace Guiomar en San Sebastián. Algo más tarde, volverá a Villaine a recoger sus 
obras. Al volver a San Sebastián se le romperán algunas esculturas. En octubre se instalará en Hernani ${ }^{1}$.

En la actualidad se conservan 264 dibujos en el Museo Chillida-Leku², algunos de ellos fechados en 1948 (por tanto, anteriores al viaje a Paris). De las esculturas han quedado las denominadas: "Torso", "Yacente, versión 1", "Yacente, versión 2", "Concreción" y "Forma". Conservamos fotografías de "Pensadora", "Maternidad" y un relieve ${ }^{5}$ de 1949.

La recreación de esta etapa la voy a hacer, en primer lugar, a partir de cómo fue presentada en la Exposición Retrospectiva que se presentó en el Museo Nacional Centro de Arte Reina Sofía, entre el 15 de diciembre de 1998 y el 15 de marzo de 1999. En segundo lugar, nos asomaremos al recuerdo que el matrimonio tenía de esos años en la película "Chillida, el arte y los sueños: memoria de las filmaciones con mi padre" de Susana Chillida, hija del artista, realizada entre 1990 y 1998. En tercer lugar, veremos cómo la evoca Chillida en una entrevista realizada por Martín de Ugalde en $1975^{7}$.

Tres evocaciones, tres "construcciones" de un personaje, un Chillida joven -de los veinticuatro a los veintisiete años-, que se realizan en tiempos distintos de la vida del artista: las dos primeras, cuando tiene ya más de setenta años, y la tercera, con 51. Susana Chillida, en su documental, "construye" su propio relato a partir de secuencias que va filmando -"persiguiéndole cámara en mano", suele decir ella-y, también, utilizando filmaciones antiguas. Secuencias, en su mayoría, muy breves, donde se nos muestra al artista dirigiéndose a la cámara, a su hija, a Pili y a algunos amigos. Todos hablan sobre él, su obra, su vida, sus proyectos... Hay varios hilos conductores. Uno, muy importante, es mostrar cómo de la relación tan especial que Chillida tenía con la luz del día y de la noche, con el horizonte y con el mar, con la casa y la familia, van surgiendo sus obras: el "Elogio del Horizonte", el "Peine del Viento", la casa de Zabalaga, el proyecto Tindaya. Así, en el documental, la hija "construye" su personaje; como antes lo había hecho

\footnotetext{
${ }^{1}$ Los datos biográficos han sido obtenidos básicamente en Chillida, 1948-1988, Catálogo de la Exposición, Museo Nacional Centro de Arte Reina Sofía, 15 de diciembre de 1998-15 de marzo de 1999, pags. 286-337 y confrontados con las aportaciones del mismo Chillida en los dos documentos que se analizan en este artículo: Chillida, S., Chillida, el arte y los sueños: memoria de las filmaciones con mi padre, Universidad del País Vasco, 2003 y de Ugalde, M., Hablando con Chillida. Vida y obra. Donostia-San Sebastián, Txertoa, 2007.

${ }^{2}$ Agradezco a Nausica Sánchez, responsable de los archivos del Museo, su valiosísima colaboración al haber puesto a mi disposición todo ese material.

${ }^{3}$ Ver Schmalenbach, W., Eduardo Chillida. Dibujos. Barcelona, Polígrafa, 1979, p. 4.

${ }^{4}$ Ibidem, pag. 6.

${ }^{5}$ VV.AA. 1999, op. cit. (nota 1), pag. 290.

${ }^{6}$ Chillida 2003, op. cit. (nota 1).

${ }^{7}$ Ugalde 2007, op. cit. (nota 1).
} 
Martin de Ugalde en su entrevista; más tarde, el comisario de la Exposición, con el modo de disponerla, y yo, con ustedes, con el relato que voy haciendo. A ese personaje que va resultando le ponemos un nombre: "Eduardo Chillida".

Al hilo de las diversas evocaciones presentaré algunas de las obras realizadas por Chillida en esta etapa. E iré desplegando un determinado modo de aproximación a la obra de arte, que me gusta denominar "escuchar el arte". Así decía Chillida respecto a la materia que trabajaba, "escuchar" lo que dice el hierro, la madera, el alabastro... Escuchar el arte, así, en infinitivo, porque no se trata tanto de un método, sino, más bien, de una cierta actitud hacia el arte, una cierta predisposición que hace posible, en ocasiones, el que la obra de arte nos impacte, nos diga algo, nos interpele... Tal modalidad de aproximación a la obra de arte marca ciertas diferencias con la que acostumbran los historiadores del arte y los filósofos. Aquellos suelen preocuparse más en situar a los autores, o a las tendencias artísticas, en el periodo sociocultural en que se producen las obras, a contrastarlas con las de otros autores, a buscar semejanzas y diferencias con otras obras, anteriores o posteriores en el tiempo y, así, mostrar lo específico del autor o de la tendencia. Los filósofos, por su parte, cuestionarán su propio bagage de reflexión con las percepciones que se producen en la contemplación artística. Recordemos a Heidegger ante las famosas botas de campesino de van Gogh o Deleuze ante la pintura de Bacon.

La actitud que he denominado "escuchar el arte" -desprendida de los planteamientos de Freud- está atenta al impacto que se produce en el contemplador, hasta qué punto le lleva a la confrontación con su propio psiquismo. Actitud de escucha que "deja de lado" la preocupación de llegar a una conclusión -como el psicoanalista en sesión deja de lado su afán por curar-y "se deja estar" en ese entrecruzamiento de sensaciones, de imágenes, de pensamientos, de afectos... El contemplador del arte anima la esperanza de que sólo desde este dejarse estar algún significado caiga del lugar en que lo tenemos colocado, caiga -eso es el lapsus, una caída- y encuentre ahora otro distinto. Y así nacerá algo, no sabe del todo qué, algo que a partir de un trazo -visual, sonoro, olfativo, táctil- invada su psiquismo e intente articularse como lenguaje; es decir, intente ser comunicado a través de la palabra.

Recordemos a Freud volcado en la contemplación de un solo cuadro de Leonardo , el de "Santa Ana, la Virgen y el niño", cuando, al hilo de la famosa percepción del buitre o milano en los pliegues del manto de la Virgen, tan evidente para Otto Rank, se queda detenido en una línea del Diario de Leonardo:

${ }^{8}$ Freud, S. «Un recuerdo infantil de Leonardo de Vinci» (1910), en Obras Completas, Buenos Aires, Amorrortu, vol. XI, págs. 53-128. 
la que repetía, en un lapsus, la hora en que había muerto su padre... O en esas vacaciones en Roma, tres semanas, acudiendo todas las mañanas a la Iglesia de San Pietro in Vincoli, entonces casi a oscuras, para contemplar al "Moisés" de Miguel Angel ${ }^{9}$. Contemplarlo desde todos los ángulos posibles, medirlo, dibujarlo, hacerlo vivo. En esa contemplación se le hace real el relato de la Torá que narra el episodio de la revelación de la Ley a Moisés en el Monte Sinaí. Freud lo contaría años después: fue tan impactante que llegó a esconderse en un rincón de la iglesia temiendo que cayera sobre él la ira de Moisés... Sólo así pudo librarse de los comentarios de los críticos de arte y dar su propia versión, equivocada o no, sobre el momento preciso, dentro del relato bíblico, en que Miguel Angel esculpió su Moisés ${ }^{10}$.

\section{La Exposición del Museo Reina Sofía}

Cuando visito un museo o una exposición doy mucha importancia a la disposición de las obras, los espacios que ocupan -o mejor, que crean-, la iluminación, los textos explicativos; es decir, a cómo han dialogado con el artista los que han organizado la exposición y a cómo lo transmiten al público. Pues en la selección de la obra de un autor o de una época y en su ordenación en el espacio se pretende un diálogo con el contemplador a fin de que, en la medida de lo posible, pueda "encontrarse" con ella. Tomaré, pues, como punto de partida, lo que, en mi recuerdo, fue el "encuentro" con la obra de Chillida en la Exposición del Reina Sofía.

\section{Las esculturas}

A la entrada de la Exposición, un pequeño espacio, claramente separado del resto, y con muy baja iluminación, como es habitual cuando se trata de dibujos. En el centro, con suave luz focal, reclamando la atención, tres esculturas, esbozos de cuerpos mutilados y sometidos a un intenso proceso de depuración, que recuerdan las de la antigua Grecia. Chillida ha hablado en muchas ocasiones de cómo le interesó la Grecia clásica y, más aún, la pre-clásica, y cómo con

\footnotetext{
${ }^{9}$ Freud, S., «El Moisés de Miguel Ángel»(1914), en Obras Completas, Buenos Aires, Amorrortu, vol. XIII, págs. 213-240.

${ }^{10}$ Tuve ocasión de analizar esta actitud ante el arte en «Contemplación artística y escucha analítica. A propósito de Velázquez, pájaro solitario, de Ramón Gaya», en Escritura e imagen, vol. 7 (2011), pp. 77-98.
} 
frecuencia iba al Louvre a contemplar lo que allí se exponía. Quizá estamos demasiado acostumbrados a contemplar las esculturas griegas tal como nos han llegado, en su mayoría mutiladas, y hemos amortiguado el efecto siniestro que suele provocar la visión de un cuerpo mutilado.

La primera, "Torso", de 1948, (Fig. 1), en yeso, un torso masculino, rígido, estilizado al máximo -con predominio de ángulos y líneas rectas-, como si hubiera sido sesgado con una sierra circular a la altura del cuello y justo por debajo de los genitales. No hay tampoco brazos. Visto de manera frontal, la zona correspondiente a pecho, cintura y pelvis forma una superficie plana. Tal superficie correspondería a la parte superior de un tronco de pirámide de base rectangular que viéramos desde arriba, de tal modo que la base del tronco correspondería a la espalda de ese torso. En esta estilización de la figura, los genitales apenas se esbozan. ${ }^{11}$

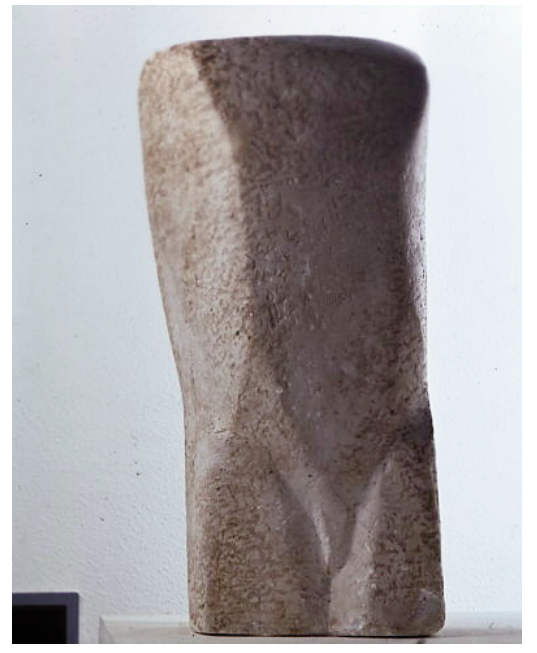

Torso. Catálogo Exposición Reina Sofía, p. 125

La segunda, "Yacente 1", de 1949, (Fig. 2) ha sido colocada, en clara contradicción con el título, en vertical... Se trata de un segundo torso masculino, rígido también, cortado al comienzo de los muslos, que reposa sentado sobre una base cilíndrica -en perfecta proporción con la figura- formando un conjunto que acentúa la verticalidad. El brazo derecho, cortado a la altura de la muñeca, dirige hacia adelante el codo y, rodeando la cabeza, vuelve bruscamente el antebrazo

\footnotetext{
${ }^{11}$ Una reproducción en bronce se encuentra en el Castillo del Monte Urgull de San Sebastián. Fue un regalo que hizo Chillida a la ciudad, en homenaje a su amigo Perico Arana a quien le gustaba mucho el original en yeso.
} 
hacia la axila izquierda, mientras el izquierdo se eleva en diagonal por encima de la cabeza y hace retroceder el antebrazo -cortado a la altura de la mano- hacia la parte de atrás del cuello. La parte anterior del torso, desde el cuello hasta la pelvis, es plana, sin ninguna insinuación de pectorales, al modo del "Torso". Llama la atención la altura y rigidez de esta zona. El dramatismo de la figura proviene del tratamiento de los brazos: como si protegieran la cara de algún peligro externo, algo que el sujeto ha visto e intenta evitar...

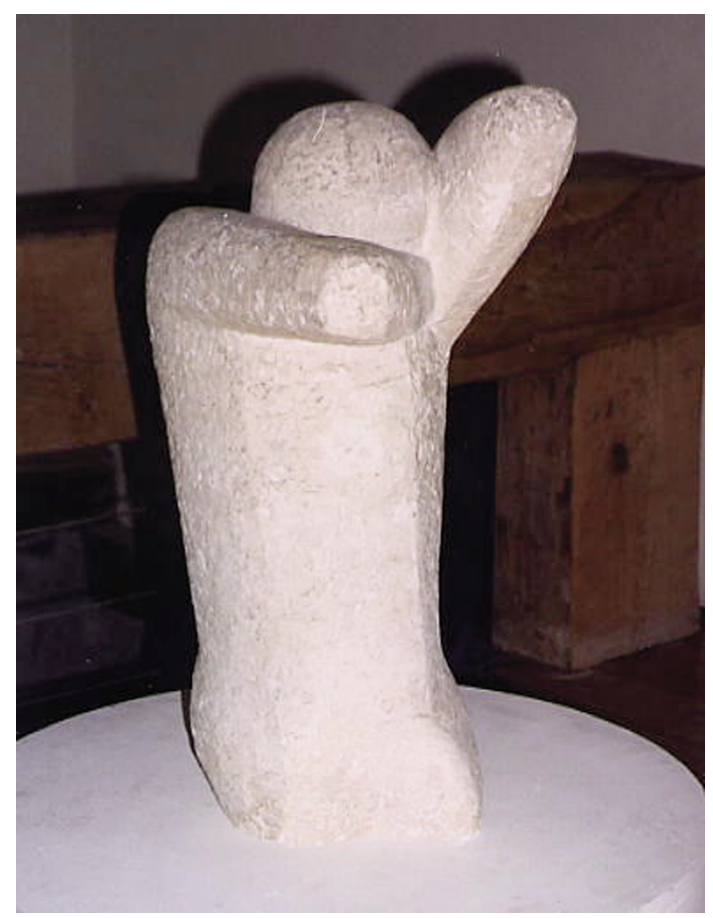

Yacente 1. Catálogo Exposición Reina Sofía, p. 126

(Más tarde, en el Museo Chillida-Leku, tuve ocasión de contemplar una escultura, variante de Yacente, 1, y que podemos denominar "Yacente, 2" (Fig. 3 ), expuesta, ahora sí, en posición horizontal ${ }^{12}$. La pierna izquierda, flexionada al extremo, ha quedado cortada a la altura del tobillo y ofrece base a la figura toda; la derecha, cortada hacia la mitad del muslo, se prolonga, rígida, en horizontal, en la dirección del torso. Ahora, la escultura ha adquirido mayor dramatismo debido, precisamente, al movimiento de brazos y piernas en contraste con la rigidez del torso.)

\footnotetext{
${ }^{12}$ Así se expone en el Museo Chillida-Leku.
} 


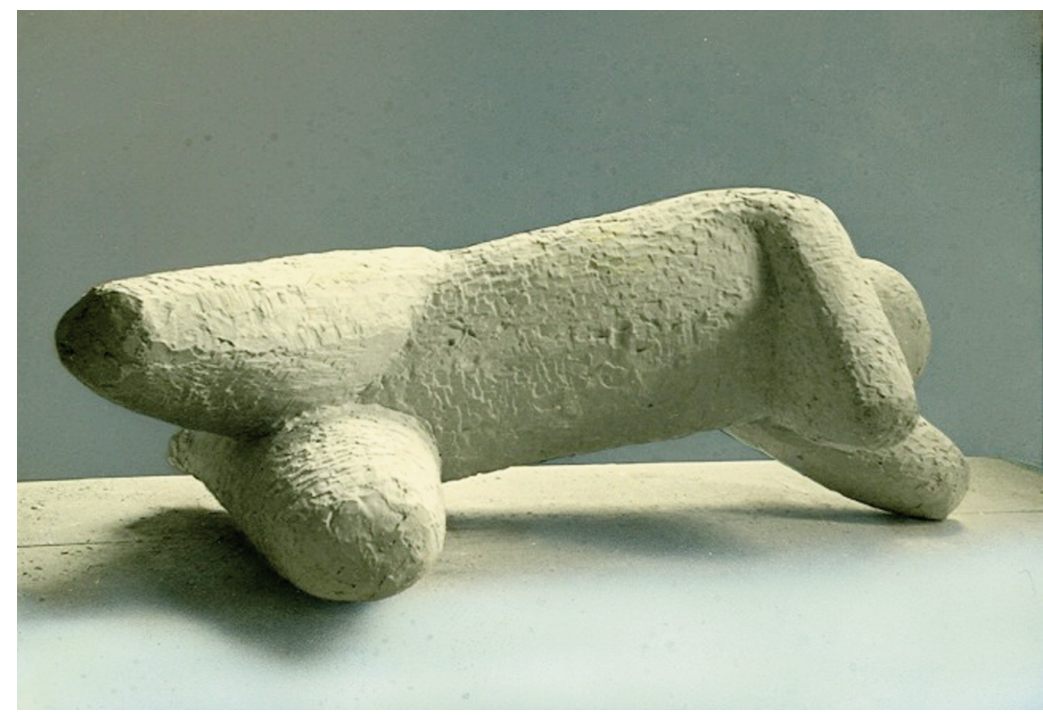

Concreción. Catálogo Exposición Reina Sofía, p. 127

Y la tercera, "Concreción", de 1950, (Fig. 4), realizada en piedra, donde se hace más presente el anhelo de no-figuración que caracterizará toda la obra posterior de Chillida. Sólo por referencia a las anteriores, podemos percibir una forma humana femenina. Es, quizá, la escultura que evoca mejor los trabajos de su admirado amigo Brancusi, si es que no es un homenaje explícito...

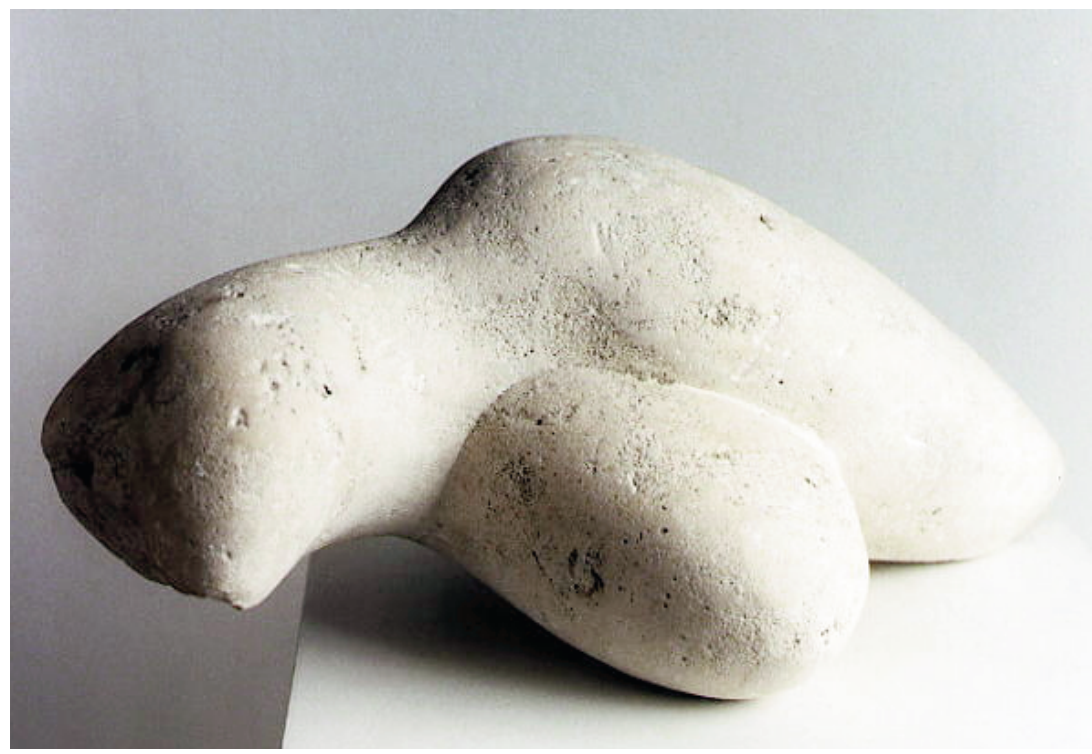

Yacente 2. Archivo Chillida-Leku 
Eché en falta "Forma", de 1948, (Fig. 5), un esbozo de cuerpo de mujer, que se nos muestra sentada, sin cabeza, ni brazos; la pierna izquierda, cortada a la altura de la rodilla, se eleva ligeramente del suelo, mientras la derecha levanta con energía el muslo y, cortada a la altura del tobillo, se apoya en vertical sobre el suelo. Entre tanta mutilación de cabeza y miembros percibimos el movimiento suave del busto hacia adelante: en pronunciada torsión, acaricia con el pecho derecho ese muslo que, ahora, pareciera levantarse buscando la caricia.

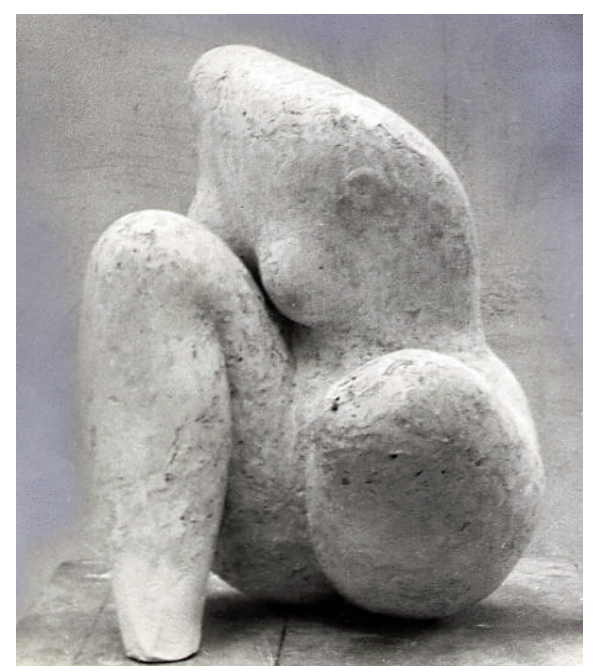

Forma. Archivo Chillida-Leku

Es conmovedor ver cómo Pilar Belzunce, en la película "Chillida, el arte y los sueños", acaricia esta escultura mientras, con orgullo, va diciendo: "Su primera, primera obra de verdad fue ésta. Y esta escultura se expuso en París en el Salón de Mayo" "13. En alguna foto antigua familiar, incorporada a la película, aparece Pilar, sola, en un jardín, sentada, y, un poco en alto, la "pareja" que forman "Torso" y "Forma"...

Pues es claro que las dos esculturas han formado pareja a lo largo de los años. En la entrevista con Martín de Ugalde, de 1975, en la que me detendré más adelante, Chillida se refiere a ellas: "Bueno, lo figurativo que hice en este primer tiempo fue eso, de lo que me quedan dos torsos tallados en yeso, uno de mujer y otro de hombre, porque durante el traslado desde París en tren se me rompieron algunos. Estos dos los he expuesto muchas veces por el mundo. "14

${ }^{13}$ Chillida 2003, op. cit. (nota 1), p. 188.

${ }^{14}$ Ugalde 2007, op. cit. (nota 1), p. 62. 


\section{Los dibujos}

Pero volvamos al Museo Reina Sofía. Después de detenerme en la contemplación de las esculturas, dirigí mi atención a los dibujos. Tuve que adaptarme a la penumbra en que se presentaban -como si se restaran importancia a sí mismos-y los fui contemplando, sin especial preocupación por fijarme en cada uno...

Volví pasados unos días. Mi retina conservaba todavía el impacto de las esculturas. Se presentaba un total de doce dibujos de línea del periodo que estamos recorriendo: cuatro de 1948, cinco de 1949 y tres de 1951. Menos uno, de 1949, que representa una mano, los demás son desnudos femeninos ${ }^{15}$. Apreciamos en ellos cuerpos de formas voluminosas, predominantemente sedentes o recostados sobre el suelo, trazados con línea muy estilizada. Dan la impresión de seres cansinos, como que parecieran buscar el suelo. Las manos suelen sostener las cabezas; éstas, en ocasiones, se inclinan hacia abajo con una cierta violencia. No aparecen nunca los rasgos de la cara. Los cuerpos - cuando hay más de uno- se apoyan unos en otros. A veces, se funden en transparencias.

Detengámonos en algunos de ellos, siguiendo la secuencia cronológica ${ }^{16}$.

De 1948, seleccionamos el segundo, "Sin título", (Figura 6). Representa a una madre con su hijo, ya no bebé. Ambos están desnudos. Las nalgas del

\footnotetext{
${ }^{15}$ A continuación hago una brevísima descripción de los mismos:

Los dibujos de 1948. El primero, tres voluminosas mujeres de pie, muy juntas, dos de espaldas y una de perfil, con las cabezas agachadas, una de ellas reposa su mano sobre el hombro de otra; el segundo, una madre de frente, sentada, con un niño sobre su pecho, que se vuelve hacia ella y la abraza; el tercero, una mujer sentada cayendo hacia atrás, que parece sujetarse apoyando la mano derecha sobre la rodilla derecha, que está levantada, y con la mano izquierda sujetándose la cabeza; el cuarto, una mujer de espaldas, también cayendo, mirando hacia arriba y con la mano derecha que parece taparse la boca.

1949. El primero, mano izquierda fuertemente cerrada, el pulgar, situado arriba, se aprieta también contra el resto de los dedos; el segundo, mujer de frente, tumbada, apoya su cabeza sobre la mano derecha, el codo reposa sobre otra mujer que aparece fragmentada; el tercero, dos mujeres sentadas: una de ellas en posición frontal, con la cabeza reposando a la vez sobre las dos manos y de éstas, la izquierda sobre la rodilla derecha; la segunda, también sentada, de espaldas, el codo izquierdo sobre la rodilla izquierda y la cabeza muy agachada; el cuarto, una mujer sentada recostada sobre otra (o, quizá, un hombre) que aparece en escorzo; el quinto, dos mujeres, una recostada sobre otra, ambas se sostienen la cabeza con las manos.

1951. El primero, fragmento de desnudo de mujer echada sobre su espalda y donde aparece la cintura, vagina y parte de los muslos; el segundo, dos figuras sentadas, reducidas a segmentos lineales, excepto las cabezas, que aproximan sus brazos; el tercero, las dos figuras anteriores han adquirido tridimensionalidad.

${ }^{16}$ He tenido ocasión de hacer un análisis de estos dibujos en una secuencia que se extendía por las esculturas "Ilarik" (1951), "Yunque de sueños, IX" (1959) y "Peine del viento" (1977), en "Chillida, yunque de sueños», VIII Simposium de la Asociación Psicoanalítica de Madrid, "Los sueños: cien años después", Revista de la Asociación Psicoanalítica de Madrid, (1999) pp. 101-114.
} 
niño, la pierna izquierda y la cabeza, fundidos en transparencia con la madre. La parte inferior de las piernas de ambos queda sin dibujarse. Al contemplar las figuras tenemos la impresión de que, junto con la escena que vemos, se nos sugiere un momento inmediatamente anterior: madre e hijo estarían sentados plácidamente, el hijo recostando su espalda sobre el regazo de la madre. De pronto -y ésta es la escena que se nos ofrece- el niño se ha girado bruscamente hacia la derecha, se echa al cuello de la madre y la abraza con fuerza. La madre, sorprendida, como que hubiera perdido el equilibrio y lo recuperara apoyando su mano izquierda sobre el suelo, para sostener el peso de ambos cuerpos. La mano derecha se ha dirigido hacia detrás del cuello para aflojar, quizá, la presión que ejercen las manos del niño.

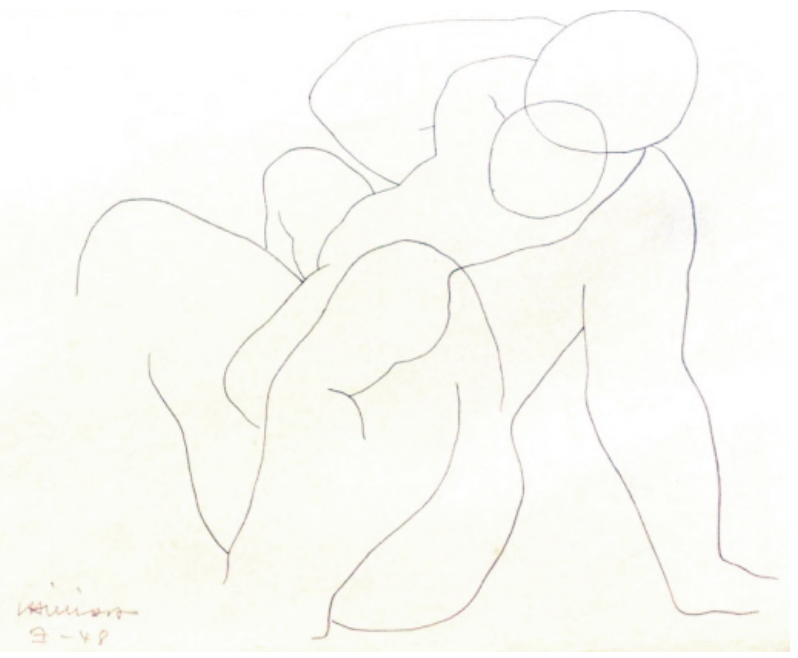

Sin título. Catálogo Exposición Reina Sofía

De 1949, fijémonos en "Desnudo", (Figura 7), que representa dos desnudos femeninos. Son posturas que aparecen, con diversas variantes, en la dibujística de esta etapa. Como si el empeño de Chillida fuera encontrar para ellas una postura en la que la relajación hubiera llegado al extremo. Especial atención merece el tratamiento de las cabezas: un simple círculo, generalmente caído respecto a los hombros, y sostenido por una mano o por las dos. En ocasiones las cabezas aparecen erguidas y sujetadas por ambas manos, con gestos que hacen pensar en plañideras. En este caso, ambas mujeres están sentadas -la de la izquierda en posición frontal y la de la derecha, de espaldas-, sin ninguna comunicación entre ellas -algo que se repite en esta serie-. Dan la impresión de estar dormitando. En la figura que está a nuestra izquierda llama la atención el volumen de sus piernas, especialmente la derecha. El muslo recibe el peso 
del antebrazo que, a su vez, recibe el de la cabeza. El antebrazo izquierdo busca también el mismo muslo para apoyarse. La pierna izquierda, doblada, descansa sobre el suelo. El antebrazo derecho parece haber estado apoyado, hace un momento, sobre la misma rodilla, y haberse ido resbalando poco a poco... La figura de la derecha es una variante de una serie de figuras en la misma posición. En una de ellas aparece el nombre de Pili. Casi, casi como un ejercicio de dibujo de una sola línea en la que Chillida intentara captar una determinada postura de su modelo.

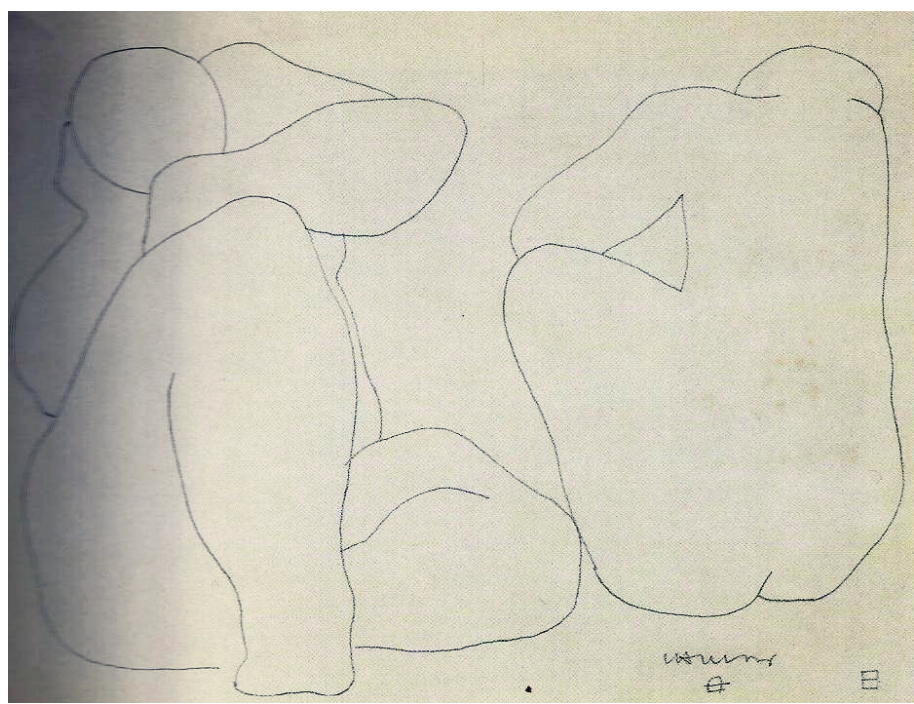

Desnudo. Catálogo Exposición Reina Sofía

Y de 1951, detengámonos en "Figuras” y "Sin título", (Figuras 8 y 9). Observamos dos cuerpos humanos sedentes -ya no es posible decidir si se trata, como hasta ahora, de figuras femeninas- en cuyo tratamiento se ha optado por la línea recta. El contraste entre los dos dibujos permite apreciar cómo se van introduciendo volúmenes cubistas, si bien sólo en las zonas de aproximación entre ambas figuras. Los trazos van perdiendo el carácter figurativo de las formas que hemos visto hasta aquí. Me parece significativo advertir cómo las figuras se buscan una a otra, como si fueran a ensamblarse, ${ }^{17}$ precisamente ahora cuando han perdido el carácter figurativo... Será característico de las esculturas de Chillida este movimiento de volúmenes que se buscan, se abrazan, se interpenetran, se abren al espacio... Y, así, lo crean.

${ }^{17}$ Ensamblaje que anticipa los trabajos en madera de esta década. Recuérdense los "Abesti gogora" ("Canto rudo"). 


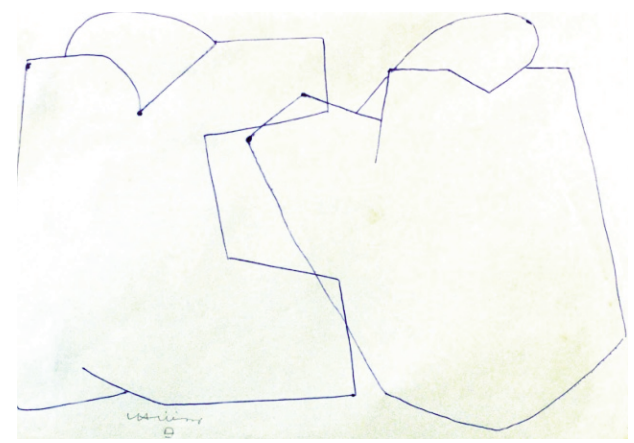

Figuras. Catálogo Exposición Reina Sofía

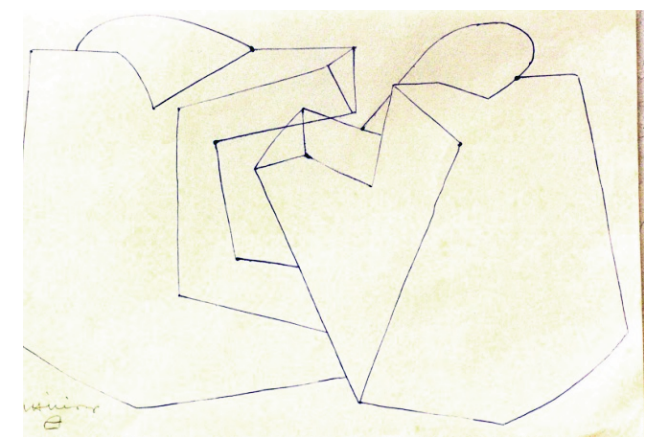

Sin título. Catálogo Exposición Reina Sofía

¿Qué decir sobre estos dibujos?

Lo primero de todo es que se ha hecho una selección de entre 264 dibujos, mayoritariamente de línea ${ }^{18}$. Y que, considerado todo el conjunto, la selección ha procedido a presentar desde una determinada perspectiva el paso de la figuración a la no-figuración. A partir de las imágenes elegidas (en las que se supone que prevalece la armonía, la proporción de las formas, la placidez de las figuras), la "llegada" a la no-figuración puede entenderse como el final de un "proceso melódico".

Es ésta la metáfora que "organiza" la visión de los dibujos de esta época en el conocido análisis de los mismos realizado por Werner Schmalenbach ${ }^{19}$, tras haber seleccionado 24 dibujos de desnudos femeninos, todos de línea. "El artista utiliza el motivo del desnudo como pretexto para llevar a cabo una reflexión estética sobre el espacio. (...) el cuerpo constituye todavía una unidad en sí misma, y sus perfiles fluyen como ininterrumpida melodía. (...) En los dibujos que, en contraposición a las esculturas, obtienen la sustancia vital del movimiento lineal, el proceso melódico sigue siendo determinante, por lo que vienen a constituir algo radicalmente alejado de la obra posterior y "genuina" del artista".

Refiriéndose a la obra escultórica de esta etapa, comenta: "Desde un principio se puso de manifiesto que el interés no iba dirigido al cuerpo en sí, como tampoco a una "expresión" que se materializara en él, sino sólo a las posibilidades que este cuerpo ofrecía para una modelación plástica elemental. El interés se centraba, pues, en el lenguaje "puro" de los volúmenes, en el arte del contrapunto plástico y en el dominio técnico de la piedra, del yeso y de la arcilla”. [Cursivas mías, E.Ch.]

\footnotetext{
${ }^{18} \mathrm{Si}$ atendemos a la agrupación de figuras nos encontramos con 92 en los que aparece una mujer sola, 75 de dos mujeres, 19 de tres o más mujeres. En 7 dibujos aparece una madre con un niño, en 11 sólo hombres, y el resto, 60 dibujos de diversa temática.

${ }^{19}$ Schmalenbach 1979, op. cit. (nota 3), págs. 3-6.
} 
Llama la atención la rotundidad en afirmar que la obra de este período no responde a un deseo de expresión personal de la propia subjetividad, sino a "llevar a cabo una reflexión estética sobre el espacio". Más adelante, radicaliza aún más su expresión: "Su autor no es Chillida hombre con sus apetencias expresivas, sino su mano de dibujante, el lápiz o la pluma, junto con la voluntad de alumbrar formas. Naturalmente, todo esto es inseparable del hombre. Pero aquí lo personal no accede a primer plano. Todo es función de la forma objetiva".

Resulta difícil sostener estas afirmaciones. No hay más que contemplar esos desnudos de mujeres, en su mayoría de espaldas, como huyendo de la mirada del espectador, desplomadas sobre el suelo, o sentadas buscando un apoyo, o con las manos sujetándose la cabeza en gesto más de desesperación que de reflexión, para apreciar el impulso expresivo que anima estos dibujos. Impulso expresivo que aparece más acentuado si atendemos a los otros dibujos de Chillida, en esos mismos años.

\section{Los "otros dibujos" de Chillida}

Dada la cantidad de dibujos que figuran en el Archivo Chillida-Leku, y dados los límites de la Revista, me limitaré a una presentación mínima de los otros dibujos a que me estoy refiriendo. Selecciono cuatro de ellos a los que doy un nombre descriptivo.

"Maternidad" (Fig. 10). Se trata de un dibujo de líneas gruesas y tinta aguada, que configuran el perfil cerrado de la figura de una madre, en posición frontal, desnuda, de cuerpo deforme -especialmente por la ausencia de cuello y el grosor de las piernas-, sentada, encogida sobre su bebé al que aprieta fuertemente contra su pecho. Una línea fina recorre todo el perfil, como envolviéndolo, en algún momento formando arabescos, y, en otros, reforzando las dos cabezas. Nuestra mirada queda literalmente clavada en su mano derecha, en el centro geométrico del dibujo: dedos muy gruesos, tensos, exageradamente abiertos, como garras que se prolongan en uñas alargadas. Inspirada claramente en las manos que estamos acostumbrados a ver en Picasso $^{20}$, no volverá a aparecer en el resto de la obra dibujística de Chillida. Sostiene la cabeza del bebé. El cuerpo de éste es también deforme: cabeza muy agrandada, mano izquierda diminuta que busca el pecho de la madre, escaso tronco y piernas,

\footnotetext{
${ }^{20}$ El dibujo muestra un claro parecido a la "madre con el hijo muerto en brazos" del Guernica.
} 
como las de la madre, muy gruesas. Los pies son grandes con relación a la mano izquierda, apretados contra las piernas de la madre. Ésta gira con violencia su cabeza mirando hacia arriba con gesto -o grito- de desesperación. E1 bebé, de rostro muy desdibujado, mira en la misma dirección que su madre. Se percibe el esfuerzo con que intenta gatear por las piernas de la madre y apretarse también él a ella al percibir su grito desgarrador... Unidos madre e hijo en ese asfixiante abrazo y en esa mirada orientada hacia el cielo. Vemos, como en el dibujo de la Figura 6, un bebé que busca a su madre. Allí, una imagen placentera, lúdica; aquí, una imagen de angustia y desesperación.

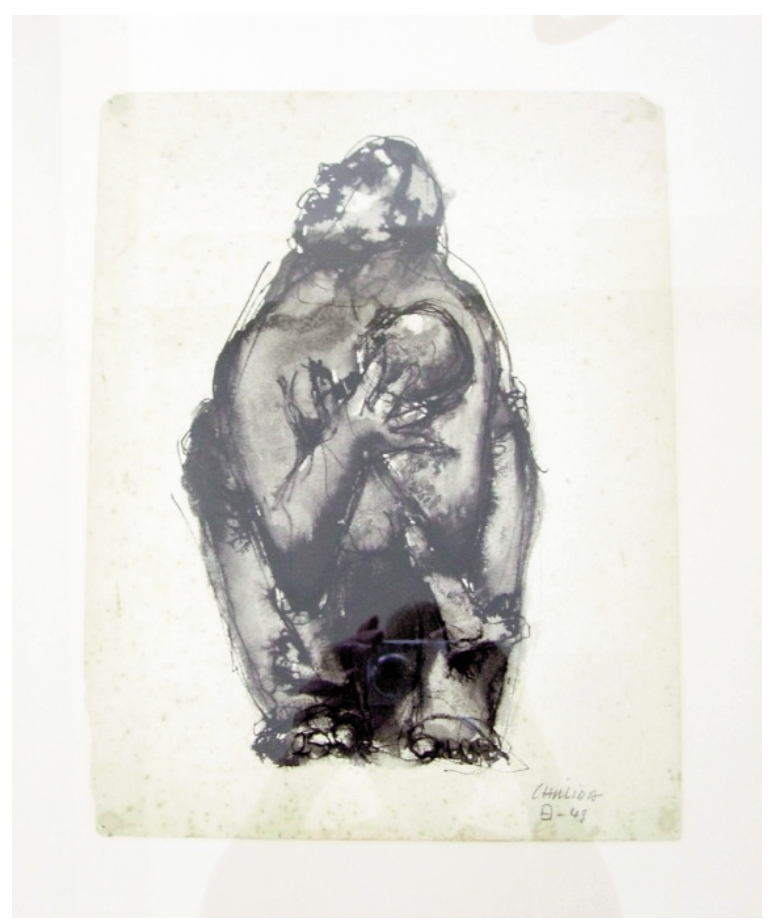

Maternidad. Archivo Chillida-Leku

"Hombre desnudo sentado" (Fig. 11). Si en el dibujo anterior nos conmovía el grito de la madre, aquí contemplamos el desvalimiento de un hombre ante el infortunio. Dibujo de tinta china, sombras de trazos gruesos, sin los grises que veíamos en el dibujo anterior. En posición frontal, sentado, brazos y piernas encogidos, cabeza grande y calva, rostro ladeado, hacia abajo, que parece evitar nuestra mirada. Los trazos que bordean su calva y el hombro derecho muestran los "arrepentimientos" en el tratamiento de la figura: como que el autor hubiera dibujado un cuerpo ligeramente más erguido y lo fuera inclinando más y más acentuándose así el efecto de indefensión -o de humilla- 
ción- en que se encuentra... El sombreado ha dejado oculto la parte izquierda de la cara, el brazo izquierdo y genitales. Toda la zona pélvica queda acortada con respecto al conjunto.

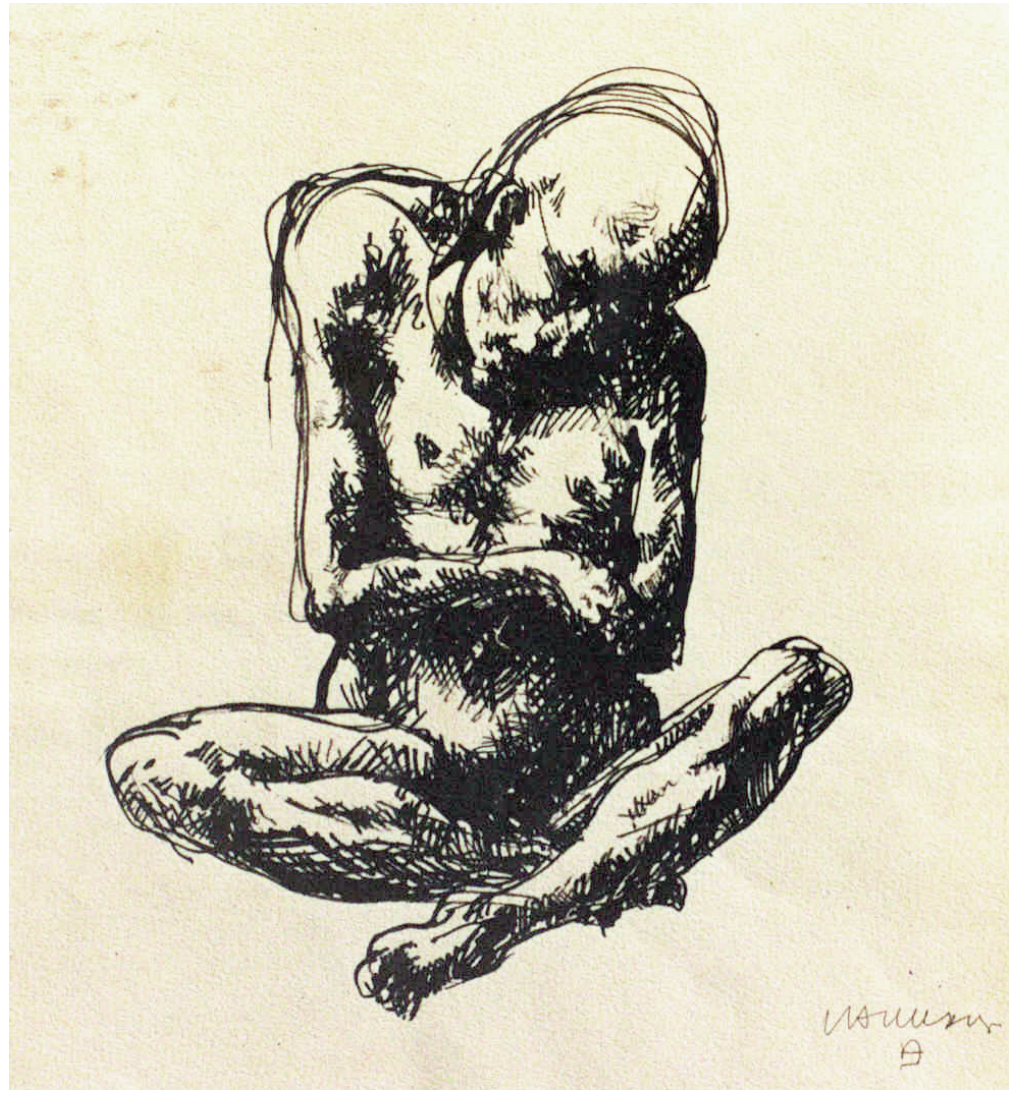

Hombre desnudo sentado. Archivo Chillida-Leku

"Crucificado, 1" (Fig. 12) El cuerpo del crucificado, como los dos anteriores, se nos presenta también en posición frontal. Han sido eliminados la cruz, las manos y los pies acentuándose así la presencia del resto del cuerpo. La cabeza ha quedado violentamente volcada hacia adelante de tal modo que no se ve el rostro. Hay una notable desproporción entre la zona superior y la inferior. En la superior, el brazo izquierdo, ligeramente flexionado, como si no hubiera quedado tensionado por el peso del cuerpo. El pecho, rígido, estrecho, sin musculatura alguna -recuerda la rigidez que veíamos en "Torso"-, en contraste con la fuerza de las piernas. La postura de las piernas da la impresión de caminar, no de formar parte de un cuerpo colgado. 


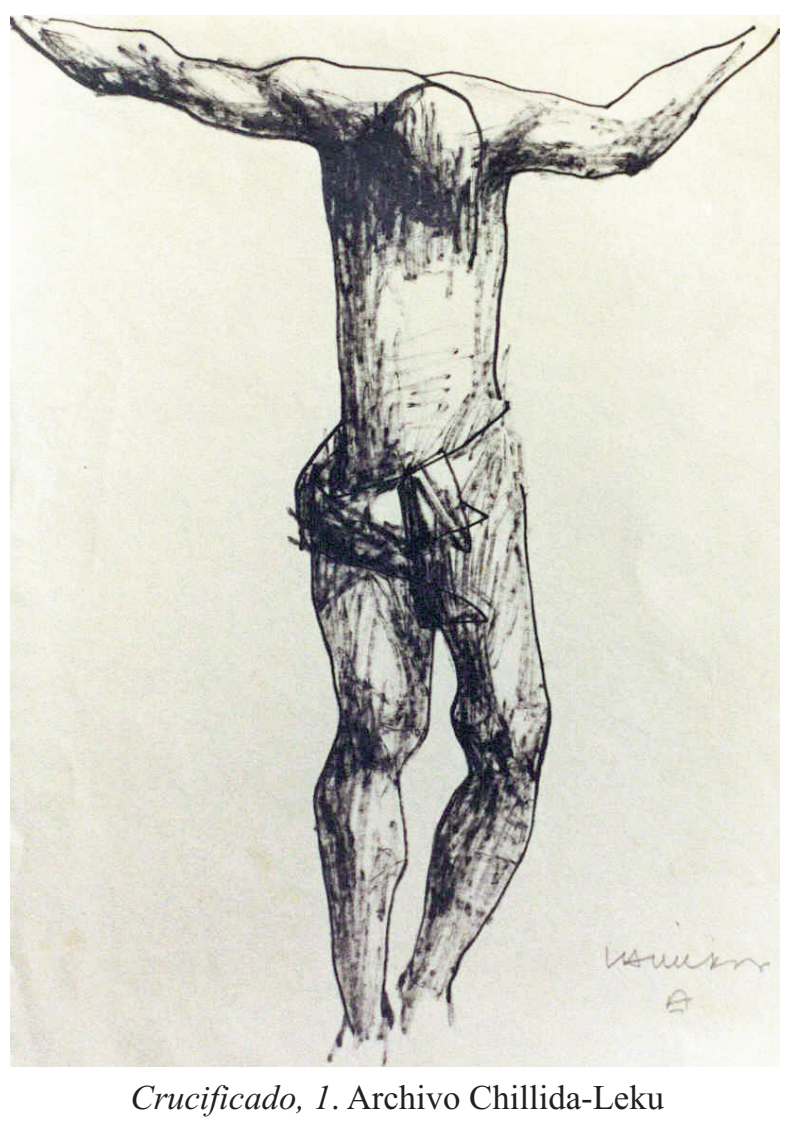

Quizá por eso, el autor haga algunas correcciones en "Crucificado, 2" (Fig. 13): se presenta desnudo, se estilizan las piernas, se subraya la sensación de rigidez de cuerpo muerto -incluso en la evitación de la verticalidad-, más acorde con la parte superior del cuerpo.

Hasta aquí, unos pocos de esos otros dibujos de Chillida. Dibujos muy distintos de los que veíamos en la Exposición. Pero que, en todo caso, se salvaron de la quema que realizaron Eduardo y Pilar y a la que me referiré enseguida... Al contemplarlos nos encontramos con alguien que se ha acercado con su lápiz al sufrimiento humano. Sufrimiento que rodeaba a nuestro artista por todas partes. Y que entonces, y durante toda su vida, encontraría en él resonancias muy intensas. ${ }^{21}$.

\footnotetext{
${ }^{21}$ Recordemos que, tras la Guerra Civil -que él pasa en Francia-, llegará a París tres años después de acabada la Segunda Guerra Mundial. Hoy, tras muchos años de desconocimiento -o conocimiento fragmentario-, sabemos el nivel de barbarie al que se llegó en la Europa de la postguerra. Ver Lowe, K., Continente salvaje, Madrid, Círculo de Lectores/Galaxia Gutenberg, 2013.
} 


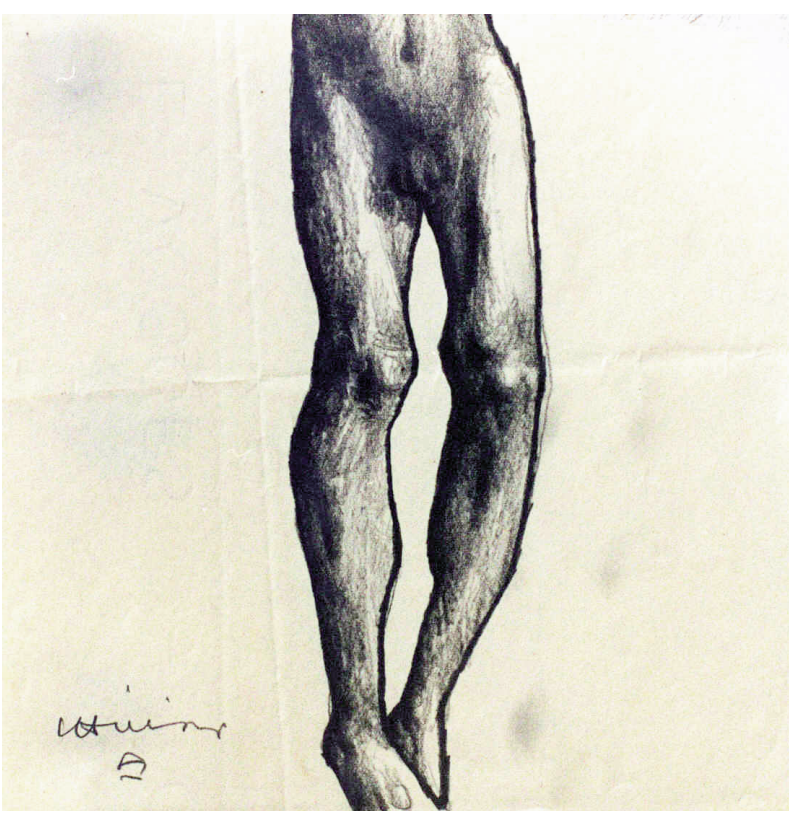

Crucificado, 2. Archivo Chillida-Leku

Pero vayamos ya a la primera de las dos evocaciones a las que me referí. ¿Cómo recordaba Chillida, cumplidos los setenta, esa etapa de juventud?

\section{La película de Susana Chillida: Chillida, el arte y los sueños ${ }^{22}$}

Detengámonos en la secuencia número 24. Primer plano de Pili dirigiéndose a la cámara: "Yo tuve la tontería, cuando me casé con él, que me dijo: "Todos estos dibujos los vamos a quemar". Y los quemamos. Los quemamos y atascamos la chimenea de casa de su madre".

Es significativo que, en el recuerdo, la quema de los dibujos aparezca asociada a la boda, y que Pili -indudablemente, en el tono de buen humor con el que siempre aparece en la película- considere la quema de dibujos como una "tontería" que se atribuye a sí misma y que se realizara en aquella casa...

Continúa el guión: "Cuando entró en la galería "Maeght" y estaba allí Clayeux, que era una persona maravillosa, con una intuición para el arte sensacional, me dijo: "Pili, jamás en tu vida vuelvas a caer en un error semejante, porque un artista cuando está creando, las otras cosas que ya ha hecho, está ${ }^{22}$ Seguiré el guión del documental, tal como aparece en Chillida 2003, op. cit. (nota 1), pp.
185-227. 
perdiendo el interés en ellas, pero son todo pasajes de su vida que nunca se deben de desechar. Tú, si te dice "quémalos", cógelos y guárdalos"”.

¿Qué dibujos destruyeron aquel día? Podemos pensar: los anteriores al viaje a París (es decir, los realizados, en gran parte, en la Academia de Bellas Artes de Madrid, en 1947, una vez que ha abandonado sus estudios de Arquitectura) y los de la etapa parisiense. Recordemos que la boda se celebra el 28 de julio de 1950, en San Sebastián. En octubre la pareja viaja a Francia, pero Eduardo evita volver a París. Sabemos, por su propio testimonio, que París le había resultado abrumador. Y acaban instalándose en un pequeño pueblo, Villaines-sous-Bois, en la región de Seine-et-Oise, donde vivía y tenía su taller Amadeo Gennarelli (19101976), conocido escultor italiano, quien les alquila un estudio y es probable que les ofreciera también su casa ${ }^{23}$. En abril vuelven a San Sebastián para el nacimiento de su primera hija, Guiomar (23 de abril de 1951). Vuelta a Villaines, esta vez solo, para recoger las obras que había dejado. Chillida está abrumado por la intensidad de la vida artística que se vive en París.

Continuemos con el guión:

Pili: En aquel momento estaba viendo tantas influencias, tantas nuevas ideas, que no sabía si esto le estaba haciendo daño o le estaba haciendo bien, entonces decidimos que mejor era irnos a Hernani, encerrarnos, y Eduardo dijo: "Y yo, si tengo una fuente en mí mismo, pues me saldrá y si no, pues mira, cuanto antes lo sepamos mejor". Era un ambiente tan fuerte que sentí que incluso me podía estar haciendo daño. Pili y yo decidimos volver a San Sebastián para ver si tenía yo algo propio que decir, liberándome de tanta posible influencia o información que me pudiera estar confundiendo. Con esta idea, en el 51, nos volvimos a casa y nos encerramos en Hernani”. Es una decisión que toma Chillida a la desesperada.

Nos la recuerda Susana. En una escena anterior (escena 8) Eduardo está hablando con su hija: "Tú ya conoces esa anécdota de París, de Villaines, que un día yo, ya desesperado, llevaba casi un año trabajando y sin conseguir hacer nada y le digo: «Pili, nos vamos a casa, estoy acabado». El año cincuenta ¿eh...? Se me queda mirando así y me dice: «Pero cómo vas a estar acabado si todavía no has empezado»".

Se trata de un momento muy importante en la vida de Chillida. Ha dejado París y ha buscado ese pequeño pueblo con la idea de alejarse de toda influencia. Y ha fracasado. Está claro: no hay otra salida. Debe abandonar Villaines y volver a casa. Lo significativo es cómo aquel momento es evocado ahora, en la

${ }^{23}$ También se había instalado allí Pablo Palazuelo con quien ya había coincidido en la Casa de España de París. 
conversación con su hija, como una "anécdota" y da por supuesto que su hija la conoce: "Tú ya conoces esa anécdota" -sin duda, es un recuerdo que debió circular mucho entre los recuerdos familiares. Y al evocarlo, tantos años después, se producen dos lapsus también significativos: sitúa el recuerdo en París e, inmediatamente, corrige: en Villaines. Y lo sitúa en el año cincuenta $-y$ recalca: "El año cincuenta ¿eh?" - cuando, en realidad, fue un año después. Son dos lapsus que van en la misma dirección: la etapa de Villaines es desmentida cuando ha sido ahí donde ha experimentado la angustia, la decepción ante sí mismo, ante el fracaso - "estoy acabado" -, si bien la negación del fracaso está colocada en Pili: "Pero cómo vas a estar acabado si todavía no has empezado?" Y Chillida recuerda cómo, al escuchar estas palabras, le entró la risa y se convenció de que ella tenía toda la razón ${ }^{24} \ldots$

Susana, en su película, ha sabido sintonizar con ese momento tan difícil que debió sufrir su padre. Tras las palabras de su madre y el comentario posterior, deja hablar a Chillida de su fracaso, de cómo ha intentado en vano superarlo, $\mathrm{y}$ de cómo se le había cerrado el horizonte: "no podía dar el paso siguiente, que, claro, era duro, era largo. Intenté, por única vez en mi vida, conscientemente, tratar de volver a hacer lo que había hecho un año antes, esos torsos que conoces de yeso. Y me dí cuenta que era incapaz de hacer aquello y entonces es cuando escribí eso que tengo escrito por ahí, "Tengo las manos de ayer, me faltan las de mañana".

Ligado al recuerdo aparecen "esos torsos de yeso que conoces" y las propias manos que los modelaron, incapaces ahora de volver a producir esas formas u otras parecidas.

El estado de ánimo de ese momento preciso lo insinúa delicadamente Susana con la presentación de la escena siguiente: sin transición alguna, la cámara enfoca una escultura de unos años más tarde. El título no puede ser más significativo: "Ikaraundi" (Gran temblor). En este momento Susana hace la siguiente acotación: "Sus brazos de hierro, avanzando por el aire, parecen palpar el espacio circundante".

\footnotetext{
${ }^{24}$ La secuencia entera nos dice cómo actúa la desmentida en la evocación de los recuerdos de esta etapa. Se trata de un mecanismo habitual en la selección de los recuerdos propios, una modalidad de defensa en que el sujeto rechaza, debido a su carácter de siniestro, reconocer algo que ha llegado a su conciencia a través de la percepción. El recuerdo permanece en la memoria consciente, pero el sujeto "mira hacia otro lado". Freud lo refiere específicamente a la percepción de la ausencia de pene en la mujer (en grado extremo, sería el mecanismo propio del sujeto fetichista) y a la percepción de la muerte (principalmente cuando se trata de la muerte de los seres queridos). Tales percepciones (que la mujer no tiene pene, que la muerte nos concierne a todos) si bien han llegado a la conciencia, el sujeto las desmiente: "no, no es verdad, la mujer no está ausente de pene", "no es verdad que yo también me vaya a morir..."
} 
Chillida está percibiendo en este momento su incapacidad para crear algo propio; por eso, intenta volver a lo que sabe que sabe hacer, esos torsos de yeso inspirados en la primitiva escultura griega de la que se había empapado en sus visitas al Louvre, volver al cuerpo, a sí mismo, a palpar los propios límites. Se ve con incapacidad absoluta de decidir ante un futuro que no está claro, que está cerrado, negro... Por eso, habla de la luz negra de su país, en contraste con la luz blanca de Grecia, si bien esa "constatación" -si puede llamarse así- sería años después, en un viaje a Grecia. Aunque él hable de decisión, no hay tal, sólo fuga. Es la única vía que abre la angustia cuando es intensa. Por eso, el título de esa escultura que la hija presenta a nuestra mirada. "Gran temblor" perteneciente a los cincuenta.

Sí, una vía de fuga y, también, de riesgo, como dice Valente: "Hay que seguir el vuelo de los grandes y no hay otra opción". Efectivamente, no hay más opción que aquello que los grandes nos han enseñado, su audacia, su afrontamiento del riesgo. En el ámbito del arte, no se trata de resolver esa angustia volviendo a lo conocido; se trata de adentrarse en lo desconocido... Continúa Valente: “¿Que en esa aventura te puedes descabezar, te puedes partir el cogote? ¡Evidente! Pero se escribe o se hace escultura o se hace pintura "pericolosamente"...

¿Qué fue lo que provocó esta angustia? ¿Qué podemos detectar a través de sus palabras? Retrocedamos veinte años y vayamos a la entrevista con Martín de Ugalde.

\section{La entrevista con Martín de Ugalde}

1975. Martín de Ugalde es un escritor y periodista vasco, tres años mayor que Chillida. Al acabar la guerra civil, exiliado en Francia. En 1940 le sorprende la invasión alemana y termina en Tetuán, alistado en un regimiento. Luego, Venezuela. Allí imparte clases en la Universidad Andrés Bello, de Caracas. En 1973 vuelve al País Vasco. Expulsado por las autoridades franquistas. Otra vez, Francia. Vuelve a España después de la muerte de Franco. Como exiliado vasco quiere saber acerca de su pueblo. Como periodista programa una serie de entrevistas con personalidades conocidas. Es en este contexto en el que solicita a Chillida una entrevista.

Señalo, aunque sea de forma tan esquemática, estos datos, pues ayudan a comprender la sintonía que se percibe entre los dos amigos desde la primera página. Asistimos a una conversación en la que ambos están dispuestos a conversar sin preocupación por el tiempo. La entrevista publicada comprende 172 
páginas. El entrevistador no pierde nunca el hilo de la conversación, pero deja hablar al entrevistado. Los temas parece que llegaran solos. En ocasiones, sólo se asoman y desaparecen; en otras, sobre todo si el entrevistador atisba que se ha tocado algún punto doloroso, él lo suscita, pues sabe bien que la conversación ayuda a curar aquel dolor, dolor que sigue buscando alivio en el relato. Y el entrevistador lo vuelve a traer, sin prisas, sin urgencias... Así cuando narran la crisis de Villaines.

Es significativo. El relato está asociado al de las esculturas que hemos visto (y dirá que buscan la luz, la luz de Grecia, y de la Grecia primitiva) y a ese momento en que se ve incapaz de seguir haciendo un arte así. En ese momento de tanta incertidumbre realiza su escultura "Ilarik", su primera obra en hierro. "Ilarik" en vasco significa "estela", estela funeraria... Luego él dirá que la estela, como, en general, todos sus hierros, evoca los instrumentos de trabajo, sobre todo, de labranza, del pueblo vasco. Podríamos decir: la estela, evoca en primer lugar, las estelas funerarias de la cultura vasca primitiva, y así sugiere el intento de Chillida por conectarse con lo más primitivo de su propio pueblo, y de todo pueblo, de todo ser humano. Ilarik, en cuanto monumento funerario, evoca un duelo, justo el duelo por la pérdida de lo que para él había sido fácil: Grecia, la luz, el tratamiento del cuerpo humano que tantas veces había dibuja$\mathrm{do}^{25}$. "Grecia era un alimento muy deseable para mí, pero no me era conveniente, no me iba a dejar seguir por donde yo tenía que seguir" ${ }^{26}$.

Por eso deja de acudir al Louvre, pues, dice a su entrevistador,

cuando pasaba por las salas griegas, ni las miraba, porque aquello era veneno para mí... Eran peligrosas para mí, podían tentarme, un poco como las sirenas a Ulises (...) y entonces, digo, de repente, un día que había llegado al Louvre y pasaba por las salas egipcias para subir luego a las de pintura por las escaleras grandes donde está la Victoria de Samotracia, me metí hacia las salas a la derecha, donde hay frescos del Renacimiento, y al pasar me encontré, de sopetón, con una vitrina en la cual había una mano mutilada que acababa de aparecer, que yo no la había visto nunca, porque era una pieza nueva, allí decían que había sido descubierta recientemente y se creía que era de la Victoria de Samotracia... Me quedé parado, porque aquello era Grecia, ¿verdad?, era un encuentro inesperado con Grecia, y además a mí las manos me

\footnotetext{
${ }^{25}$ Es curioso: habla siempre del abandono de esas esculturas, pero no del abandono de los dibujos de la misma época.

${ }^{26}$ Ugalde 2007, op. cit. (nota 1), p. 40.
} 
interesan mucho, como sabes yo dibujo mucho la mano; entonces me dí cuenta, en este momento, que ya Grecia no era lo peligrosa que había sido para mí, que ya no tenía poder sobre mí en el sentido malo de la palabra, de torcerme, porque yo ya estaba muy afianzado en mi línea fundamental... Me dí cuenta de esto cuando vi esta mano, y tuve, además, la impresión de que lo griego en esta etapa, en lugar de restarme, podía aportarme cosas... ${ }^{27}$

El párrafo se presta a diversos señalamientos. Estamos ante la irrupción de un "objeto" (algo que llega a la percepción del sujeto) y produce un efecto de extrañamiento, de siniestro $^{28}$, que, en el mismo acto perceptivo, es desmenti$d o^{29}$. Como si se dijera a sí mismo: "no, esta mano cortada no me produce angustia, al contrario, me hace sentir a Grecia como no peligrosa". Sabemos, en psicoanálisis, cómo distorsionamos las percepciones $\mathrm{y}$, en ocasiones, las vivimos transmutando el afecto. Así al afecto de angustia correspondiente a la percepción de la mano, tal como se la encontró Chillida, le va a sustituir un afecto contrario: se trata de la mano que le lleva a quitar el miedo a Grecia, a no vivirla ya como veneno, como sirena seductora... Llaman la atención las repeticiones: "una mano mutilada que acababa de aparecer, que yo no la habia visto nunca, porque era una pieza nueva" y cómo, al ser descubierta, inmediatamente es incorporada a un cuerpo, y un cuerpo bellísimo -a pesar de su mutilación- como el de la Victoria de Samotracia. "Me quedé parado, porque aquello era Grecia, ¿verdad?, era un encuentro inesperado con Grecia",30.

Inmediatamente va a ver a Pili, a contárselo, la lleva al Museo a ver la mano y le dice que tienen que ir a Grecia inmediatamente, pues ya Grecia no es temible ${ }^{31}$.

Pocas páginas después, ${ }^{32}$ vuelve a hablar de la crisis. Cita, como en otras ocasiones, en francés, a René Char: "Il faut marcher le front contre la nuit". El entrevistador le sugiere si la crisis, a los 26 años, recién casados, no tendría que ver con la angustia de pensar en un espacio para su primer hijo... Chillida

\footnotetext{
${ }^{27}$ Ibidem, p. 40. Conviene tener en cuenta que el hallazgo de esta mano es posterior a su obra Ilarik, realizada en Hernani.

${ }^{28}$ El término Unheimlich suele traducirse por "ominoso" o "siniestro". Ver Freud, S. «Lo ominoso» (1919), en Obras Completas, 17, 215-251.

${ }^{29}$ Freud distingue entre represión (Verdrängung) y desmentida (Verleugnung).

${ }^{30}$ Ugalde 2007, op. cit. (nota 1), p. 40.

${ }^{31}$ Irían a Grecia más tarde, en 1963, con Clayeux, Christine y Jacques Dupin. Allí se encontraría con la "luz de Grecia" que tanto había fantaseado en su época de París -en contraste con la "luz negra" del País vasco-. A la vuelta del viaje empieza a interesarse por el alabastro, material que le habría de permitir investigar sobre la luz.

${ }^{32}$ Ugalde 2007, op. cit. (nota 1), p.60.
} 
duda. "Yo no sé, no sé... no creo que fuera a nivel de preocupación material, no, no... era mucho más adentro, pero la cosa es que resultó algo más radical para mí... Yo nací allí, desde luego...".

Nació allí, desde luego, en esa experiencia traumática que le desequilibra. En los recuerdos esta época ha quedado asociada a una frase que repetiría continuamente: "Tengo las manos de ayer, me faltan las de mañana". Miraría sus manos, con sabañones en todos los dedos... No. No tenía tampoco las manos de ayer. No podía volver a esa etapa, sobre todo, a ese año de Villaines en el que no pudo hacer nada. En que se sintió verdaderamente acabado.

Pero, afortunadamente, pudo levantarse. Y buscó el horizonte, el mar, la luz, el cielo. Se identificó con el pájaro solitario de San Juan de la Cruz. En la película "Chillida, el arte y los sueños" le vemos abrir los brazos, contemplar las olas, como lo hacía desde muy joven, en San Sebastián, y, más tarde, desde el "Elogio del horizonte", abrir los brazos, imitar el vuelo de las aves... "lo que importa es ese pájaro que vuela de los cien que hay, y de ese pájaro lo único, lo que me importa más no es el pájaro mismo, sino su vuelo" ${ }^{33}$.

${ }^{33}$ Ibidem, p. 123. 